Editorial

\title{
Standardization, calibration and innovation: a special issue on lithic microwear method
}

\section{Keywords:}

Lithic microwear

Methodological enquiry

Surface metrology

Microscopy

Standardization

Calibration

\begin{abstract}
A B S T R A C T
This paper introduces a special issue of the Journal of Archaeological Science that considers the current state and future directions in lithic microwear analysis. There is considerable potential for lithic microwear analysis to reconstruct past human behaviour as it can provide direct insight into past activities. Consequently, it is a technique worthy of significant additional investment and continued development. To further the cause of methodological maturation within microwear analysis and to promote standardization, calibration, and innovation, the following collection of papers present various approaches and perspectives on how greater methodological refinement and increased reliability of results can and should be achieved. Many of these papers were part of a session held at the 2011 Society for American Archaeology Meeting (SAA) in Sacramento, California, while others were selected from the 2012 International Conference on Use-Wear Analysis in Faro, Portugal. The purpose of the SAA session and this special themed issue is essentially two-fold. The first is to promote awareness of the need for methodological standardization, calibration, and continuing innovation. The second is to open a serious dialogue about how these aims could be pursued and achieved.
\end{abstract}

(C) 2014 The Authors. Published by Elsevier Ltd. This is an open access article under the CC BY license (http://creativecommons.org/licenses/by/3.0/).

\section{Introduction}

Lithic microwear analysis is a technique primarily used to understand stone tool function, allowing researchers to identify past behaviours through microscopic traces left on lithic material culture. Although data collection is often qualitative, decades of rigorous research have resulted in sophisticated interpretations of prehistoric behaviours and actions. However, as a result of the subjective, nature of 'traditional' microwear analysis, interpretations made from wear traces have been met with some scepticism in the wider archaeological community. Similar scepticism has been directed towards other comparable analytical techniques, e.g. the taxonomic identification of plant microfossils (MacLeod et al., 2010). One often cited problem is that becoming a specialist is seen, inaccurately, as a fairly easy process that requires relatively little investment in time and training. While there are some established laboratories where training can be provided and some books are available that can serve as useful guides, there are as yet no widely recognized and accepted standards of practice or accredited practice guides. Although most specialists have developed their techniques of microwear analysis from a shared corpus of knowledge and many common methodological fundamentals, often passed down from experienced mentor to student, each practitioner has tended to develop his or her own way of conducting analyses.

Current practice in microwear analysis can trace its origins to the work of Semenov (1964) and other traceologists at the Leningrad Academy of Science (Levitt, 1979). Continued development of techniques by many researchers (e.g. Anderson, 1980; Grace, 1989; Keeley, 1980; Odell, 1979; Odell and Odell-Vereecken, 1980; Serizawa et al., 1982; Tringham et al., 1974) not only clarified and improved upon earlier microwear methods, but also introduced greater variability in terms of how analysts observe, identify and document wear. Despite early attempts to establish a common nomenclature (Hayden, 1979) and numerous microwear meetings and conferences over the years (e.g. Anderson et al., 1993; Beyries, 1988; Cahen, 1982; de G. Sieveking and Newcomer, 2012; Longo and Skakun, 2008; Owen and Unrath, 1986), analysis still lacks universally recognized standardization with regards to terminology and practice. Today, there remains considerable variability in many aspects of microwear research, including recording techniques and identification criteria that often lead to difficulties and inconsistencies in the presentation and evaluation of individual interpretations.

The field of microwear analysis also lacks a consistent framework for understanding wear processes. There has been progress in the ability to measure tribological interaction between the surface of the tool and that of the worked material (e.g. Anderson et al., 2006; Astruc et al., 2003; Vargiolu et al., 2007), however this work is still ongoing. Similarly, there are no consistent guidelines or criteria for identifying if lithic material is analysable based on degree of post-depositional wear. Some work has been done to clarify the issue of post-depositional wear (Burroni et al., 2002; Mansur-Franchomme, 1986) and some labs have protocols in place (e.g. Donahue and Evans, 2012) but there is no global standard or agreed upon framework for assessing assemblages prior to 
functional analysis. The lack of certainty surrounding the precision and accuracy of current methodologies that underlie many interpretative frameworks (see Evans, 2014) is also a source of tension. Some of these issues may be overcome by clarifying what constitutes best practice and agreeing on protocols which can be globalized within standardized analytical frameworks.

The contributions to this special issue offer a variety of suggestions as to how wider standardization could be realized. These papers were originally presented at two different international conferences; first was the 2011 Society for American Archaeology Meeting in Sacramento, California and second was the 2012 Conference in Use-Wear Analysis in Faro, Portugal. These presentations, the resulting papers, and this special themed issue serve two basic purposes: first to increase awareness of the need for greater standardization, reliable calibration, and innovation, and second to fuel an open and serious dialogue regarding how these aims could be pursued and achieved. Standardization is a means for effective intra- and inter-disciplinary communication and leads to greater comparability of both data and results. In tandem, a reliable means of calibrating individual datasets to an accepted standard would provide a common language to facilitate the exchange of information between researchers. This would then serve to broaden and deepen contexts for interpretation making it possible to move beyond methodological variability and enhance our collective understanding of past human behaviours. Additionally, innovation in the form of new techniques and technologies will increasingly demand the development of widely recognized standards within the field. Consistency and openness regarding all stages of the process, including recovery, artefact preparation, microscopy, data analysis, and interpretation is needed to move the discipline forward.

\section{Contributions}

The papers in this special issue cover a wide range of topics relating to the theory and practice of lithic microwear analysis. The papers explore microwear through reflective self-evaluation, experimentation, archaeological application, or a combination of these three complementary approaches. The authors also present an array of perspectives, including some conflicting opinions about the future of the discipline. The purpose in organizing the original SAA conference session and the resulting journal issue was not to collate the ideas and work of solely like-minded researchers, but rather to bring together a truly diverse set of analysts who approach the same series of long-standing issues from a wide range of perspectives. It is this sort of intellectual diversity that fuels meaningful dialogue and drives disciplinary progress. As with microwear literature in general, the papers in this issue employ a number of different conceptual frameworks and analytical methodologies. Some papers use traditional qualitative methods of microwear analysis to address methodological issues or archaeological problems, while other papers explore newer quantitative methods of microwear analysis.

Several papers in this issue employ quantitative methods of analysis to interpret microwear traces. Evans (2014), Stemp (2014), Macdonald (2014), and Ibáñez al. (2014) use a variety of instrumentation developed for the engineering field of surface metrology for the quantification of wear traces. Evans (2014) uses laser scanning confocal microscope data as an example of how high end methods could compliment an existing standardized framework to improve accuracy. Stemp (2014) provides a comprehensive review of the use of laser profilometry as a means to quantify worn surfaces. This paper outlines the strengths and weaknesses of the method, providing suggestions for future research. Macdonald's paper (Macdonald, 2014) explores the use of focus variation microscopy for microwear analysis. This relies on the same principle as focus stacking macro photography and z-stack microscopy; however, focus variation microscopy differs in that it is a calibrated system designed for surface measurement and, as such, can provide reliable results. In their contribution, Ibáñez et al. (2014) use a laser-scanning confocal microscope to differentiate between wild and domesticated cereal harvesting tools. Other techniques with a similar theme are Lerner's contribution (Lerner, 2014), which explores the potential of image analysis to systematically quantify use-related microwear using incident light microscopy. This study is the latest contribution in an ongoing program of research into lithic raw material variability and the role it plays in microwear development. This follows from pioneering work by others (e.g. González-Urquijo and Ibáñez-Estévez, 2003; Grace, 1989) and, if successful, may provide a more widely applicable technique for assessing this microwear development. Using GIS software, Schoville (2014) maps fractures on tool edges to understand assemblage level patterns of microfractures, allowing the analyst to incorporate larger sample sizes than traditional microwear analysis. As mentioned above, these papers all strive to move microwear analysis towards a more quantifiable method, although they use a range of techniques from surface metrology microscopes to image analysis software, in an attempt to standardize worn surface descriptions through mathematical means.

Two further papers review aspects of commonly used microwear methods to gain a deeper understanding of these technologies. Borel et al. (2014) compare the relative utilities of incident light and scanning electron microscopy in terms of their respective strengths and weaknesses. They assess how each can be applied in pursuit of a clearer understanding of archaeological microwear evidence. Ollé and Vergès (2014) advocate for cumulative experimental design where the same set of experimental tools are repeatedly used and analysed over several set periods of time. This allows the authors to closely and directly monitor the development of microwear on the same surfaces during the course of extended use.

Using more traditional qualitative methods of analysis, other papers present archaeological case studies to illustrate the importance of standardized methodological paradigms and showcase the capability that microwear analysis has to offer as an interpretative tool. These include the contribution by Wiederhold and Pevny (2014), who outline their own best practice through the integration of rigorous experimentation, site context, and microwear analysis to understand Paleoindian assemblages in North America. Yerkes et al. (2014) present a case study of Neolithic bifacial axes, showing how microwear analysis can result in elegant interpretations of past behaviours. These papers clearly present their methods of analysis and highlight the importance of explicit reporting of analytical steps to bolster interpretation.

Two papers tackle methodological standardization for ground stone tools. Adams (2014) reviews microwear methodology as applied to ground stone technology and discusses how the field of tribology can contribute to our methodological development. Dubreuil and Savage (2014) offer another perspective on analysing wear traces on ground stone tools.

Other papers offer more reflective narratives on the state of the discipline. Evans (2014) amalgamates published blind test data, the analysis of which highlights where current methods may be failing. This contribution will allow researchers to target contact materials that are more problematic to identify and develop new methods for identification. Iovita carries out highly controlled experiments with cast glass projectile points to assess the nature of diagnostic impact fractures as a means of identifying stone-tipped projectile use in prehistory. In another paper, Rots and Plisson (2014) offer reflections on the current state of projectile impact research and provide 
suggestions for where further development is needed. To conclude the issue, Van Gijn (2014) provides a timely reminder that qualitative methods have an important role to play in microwear research. She presents several suggestions for how researchers can standardize the traditional qualitative practice of microwear analysis and emphasizes the importance of incorporating ethnographic data into our interpretations of microwear traces.

The depth and breadth of these papers are testament to the intrinsic complexity of the discipline as it is practiced today and of microwear traces themselves. This special themed issue of the Journal of Archaeological Science is an attempt to bring the many issues and debates that characterize use-wear analysis into the intellectual spotlight to engender a meaningful and ongoing dialogue between researchers in an effort to better coordinate, on both conceptual and methodological levels, our collective efforts. In doing so, we hope to maximize the amount of cultural information retrievable from the physical evidence of tool use.

\section{Future directions}

Standardization and calibration have to both been priorities in any debate regarding the practice of microwear analysis. The analytical frameworks used in conjunction with traditional methods illustrated by the various contributions to this volume can form the basis of such a debate. The clear theme throughout the history of lithic microwear analysis is the desire and attempt to bring it to equal standing with other scientific approaches.

A move towards a more rigorous method may, however, bring with it the need to combine, or even revise, the role of traditional microscopy within broader metrology-based approaches (this is partly explored in this issue). However, these metrology-based approaches need to be utilized within a holistic methodology that includes traditional microwear techniques. In fact, the history of archaeological science illustrates that, through collaborative efforts, it is possible to foster such holism through the re-contextualizing of traditional techniques and providing wider access to new technologies. The potential of the various kinds of instrumentation available for analyses is important to understand. But it is how the instrumentation is used, what parameters are chosen to be measured and, where relevant, what kind of statistical analysis is applied to the results, that distinguish each study, for example image analysis of optical microwear traces (e.g. González-Urquijo and Ibáñez-Estévez, 2003; Grace, 1989), or metrology studies using measurements of actual tool surfaces (e.g. Evans, 2014; Evans and Donahue, 2008; Ibáñez et al., 2014; Macdonald, 2014). The full impact of new instrumentation is still unknown, and it remains to be seen how it might enhance or potentially surpass what the experienced analyst can apparently discriminate (e.g. Van Gijn, 2014). Despite these unknowns, quantification allows researchers to communicate results in a common mathematical language and advance the field of microwear analysis.

Lithic microwear analysis may eventually be based on traditional microscopy but with refined identification, recording, and interpretation criteria in place. The possibility of this alternate future is hinted at by some blind test data (e.g. Evans, 2014; Rots et al., 2006) and by the confidence inspired by the wide variety of established professionals who have contributed to this volume. Future analysis may also be based on a fully quantified automated process centred on metrology systems or a combination of traditional and quantitative approaches.

These two different futures mark end-points on a sliding scale. Standardization, along with calibration, can inform on which routes are best to follow during the course of methodological exploration. Ultimately, the future of the technique is what one makes of it. Inspiring our colleagues and the next generation of archaeological scientists will assist in affording them the opportunity to have an impact on what direction(s) the discipline will take. This is only possible if we establish widely accepted standards of practice.

The field now has a growing community where debate can be centralized and more effectively pursued. The Association of Wear and Residue Analysts (WWW.AWRANA.COM) was established by the Scientific Committee at the 2012 International Conference on Use-Wear Analysis in Faro, Portugal. One hopes that our tenet for standardization, calibration and methodological innovation is high on the agenda within AWRANA, within the discipline at large, and at future international meetings.

\section{Epilogue}

We were deeply saddened by the sudden passing of Dr. Odell not long after the meetings in St. Louis. We are indebted to him not only for his participation in the original session, but for his many, many contributions to the discipline of archaeology as a whole.

Dr. George Odell made many profound and lasting contributions to the field of archaeological inquiry, not the least of which were in the context of use-wear research. His work on low-power approaches to use-wear analysis will long continue to be an analytical benchmark within the discipline. He has inspired many archaeologists and academics, including all of the contributors to this special issue. Without the foundation he was instrumental in helping lay down, none of us could be doing the kind of work we do today. We dedicate this volume in his memory.

\section{Acknowledgements}

We would like to thank all of the contributors of both the SAA session and this special issue for their stimulating and thoughtprovoking work. We would also like to thank all of the anonymous peer reviewers for their tireless efforts in reviewing the various manuscript drafts and their insightful comments that made each paper that much better.

We also acknowledge the wonderful contributions made by the original SAA session discussants, Patricia Anderson and George Odell. Both Dr. Anderson and Dr. Odell provided many keen observations about each paper as well as meaningful insights into the state of the art in microwear analysis.

AAE was supported by the AHRC (AH/J007935/1). HJL was supported by L'Équipe Archéometrie at the Laboratoires d' Archéologie, a part of the Centre Interuniversitaire d'Études sur les Lettres, les Arts et les Traditions (CELAT) at Université Laval. DAM was supported by Fondation Fyssen and the University of Toronto. WJS was supported by Faculty Development Grant from Keene State College.

\section{References}

Adams, J.L., 2014. Ground stone use-wear analysis: a review of terminology and experimental methods. J. Archaeol. Sci. 48, 129-138.

Anderson, P.C., 1980. A testimony of prehistoric tasks: diagnostic residues on stone tool working edges. World Archaeol. 12, 181-194.

Anderson, P.C., Beyries, S., Otte, M., Plisson, H., 1993. Traces et fonction, les gestes retrouvés. In: Actes du colloque international de Liège 8, 9, 10 décembre 1990. Université Liège: Etudes et recherches archéologiques de l'Université de Liège, Service de Préhistoire, Université de Liège.

Anderson, P.C., Georges, J.M., Vargiolu, R., Zahouani, H., 2006. Insights from a tribological analysis of the tribulum. J. Archaeol. Sci. 33, 1559-1568.

Astruc, L., Vargiolu, R., Zahouani, H., 2003. Wear assessments of prehistoric instruments. Wear 255, 341-347.

Beyries, S. (Ed.), 1988. Tracéology et Technologie: Aspects Méthodologiques. Oxford, BAR International Series 411.

Borel, A., Ollé, A., Vergès, J.M., Sala, R., 2014. Scanning electron and optical light microscopy: two complementary approaches for the understanding and interpretation of usewear and residues on stone tools. J. Archaeol. Sci. 48, 46-59. 
Burroni, D., Donahue, R.E., Pollard, A.M., Mussi, M., 2002. The surface alteration features of flint artefacts as a record of environmental processes. J. Archaeol. Sci. $29,1277-1287$.

Cahen, D. (Ed.), 1982. Tailler! pour quoi faire: Préhistoire et technologie lithique II, Recent Progress in Microwear Studies. Studia Praehistorica Belgica, vol. 2. Musée royal de l'Afrique centrale, Tervuren.

de G. Sieveking, G., Newcomer, H., 2012. Human uses of flint and chert. In: Proceedings of the Fourth International Flint Symposium Held at Brighton Polytechnic 10-15, April 1983. Cambridge University Press.

Donahue, R.E., Evans, A.A., 2012. Lithic microwear analysis. In: Boismeier, W., Gamble, C. (Eds.), Neanderthals amongst Mammoths: Excavations at Lynford Quarry. English Heritage, Norfolk: London, pp. 261-274.

Dubreuil, L., Savage, D., 2014. Ground stones: a synthesis of the use-wear approach. J. Archaeol. Sci. 48, 139-153.

Evans, A.A., 2014. On the importance of blind testing in archaeological science: the example from lithic functional studies. J. Archaeol. Sci. 48, 5-14.

Evans, A.A., Donahue, R.E., 2008. Laser scanning confocal microscopy: a potential technique for the study of lithic microwear. J. Archaeol. Sci. 35, 2223-2230.

González-Urquijo, J.E., Ibáñez-Estévez, J.J., 2003. The quantification of use-wear Polish using image analysis. First results. J. Archaeol. Sci. 30, 481-489.

Grace, R., 1989. Interpreting the Function of Stone Tools: the Quantification and Computerization of Microwear Analysis. BAR International Series 474, Oxford.

Hayden, B., 1979. Lithic Use-Wear Analysis. Academic Press, New York.

Ibáñez, J.J., González-Urquijo, J.E., Gibaja, J., 2014. Discriminating wild vs domestic cereal harvesting micropolish through laser confocal microscopy. J. Archaeol. Sci. 48, 96-103.

Keeley, L.H., 1980. Experimental Determination of Stone Tool Uses: a Microwear Analysis. In: Prehistoric Archeology and Ecology Series. University of Chicago Press.

Lerner, H.J. 2014. Intra-raw material variability and use-wear formation: an experimental examination of a Fossiliferous Chert (SJF) and a Silicified Wood (YSW) from NW New Mexico using the Clemex Vision processing frame. J. Archaeol. Sci. 48, 34-45.

Levitt, J. 1979. A review of experimental traceological research in the USSR. In: Hayden, B. (Ed.), Lithic Use-Wear Analysis. Academic Press, New York, pp. 27-37.

Longo, L., Skakun, N. (Eds.), 2008. Prehistoric Technology 40 Years Later: Functional Studies and the Russian Legacy. Oxford, BAR International Series 1783.

Macdonald, D.A., 2014. The application of focus variation microscopy for lithic usewear quantification. J. Archaeol. Sci. 48, 26-33.

MacLeod, N., Benfield, M., Culverhouse, P., 2010. Time to automate identification. Nature 467, 154-155.

Mansur-Franchomme, M.E., 1986. Microscopie du matériel lithique prehistorique: traces d'utilisation, altérations naturelles, accidentelles et technologiques: exemples de Patagonie. Cahier du Quaternaire 9, CNRS, Bordeaux.

Odell, G.H., 1979. A new and improved system for the retrieval of functional information from microscopic observations of chipped stone tools. In: Hayden, B. (Ed.), Lithic Use-Wear Analysis. Academic Press, New York, pp. 239-244.

Odell, G.H., Odell-Vereecken, F., 1980. Verifying the reliability of lithic use-wear assessments by 'Blind tests': the low-power approach. J. Field Archaeol. 70, 87120.

Ollé, A., Vergès, J.M., 2014. The use of sequential experiments and SEM in documenting stone tool microwear. J. Archaeol. Sci. 48, 60-72.

Owen, L.R., Unrath, G. (Eds.), 1986. Technical aspects of microwear studies on stone tools. Early Man News 9/10/11.

Rots, V., Pirnay, L., Pirson, P., Baudoux, O., 2006. Blind tests shed light on possibilities and limitations for identifying stone tool prehension and hafting. J. Archaeol. Sci. 33, 935-952.
Rots, V., Plisson, H., 2014. Projectiles and the abuse of the use-wear method in a search for impact. J. Archaeol. Sci. 48, 154-165.

Schoville, B.J., 2014. Testing a taphonomic predictive model of edge damage formation with Middle Stone Age points from Pinnacle Point Cave 13B and Die Kelders Cave 1, South Africa. J. Archaeol. Sci. 48, 84-95.

Semenov, S.A., 1964. Prehistoric Technology. Adams \& Mackay, London, Cory.

Serizawa, C., Kajiwara, H., Akoshima, K., 1982. Experimental study of microwear traces and its potentiality (English summary). Archaeol. Nat. Sci. 14, 67-87.

Stemp, W.J., 2014. A review of quantification of lithic use-wear using lase profilometry: a method based on metrology and fractal analysis. J. Archaeol. Sci. $48,15-25$.

Tringham, R., Cooper, G., Odell, G., Voytek, B., Whitman, A., 1974. Experimentation in the formation of edge damage: a new approach to lithic analysis. J. Field Archaeol. 1, 171-196.

Van Gijn, A.L., 2014. Science and interpretation in microwear studies. J. Archaeol. Sci. $48,166-169$

Vargiolu, R., Morero, E., Boleti, A., Procopiou, H., Pailler-Mattei, C., Zahouani, H. 2007. Effects of abrasion during stone vase drilling in Bronze Age Crete. Wear 263, 48-56.

Wiederhold, J.E., Pevny, C.D., 2014. Fundamentals in practice: a holistic approach to microwear analysis at the Debra L. Friedkin site, Texas. J. Archaeol. Sci. 48 104-119.

Yerkes, R.W., Galili, E., Barkai, R, 2014. Activities at final Pre-Pottery Neolithic (PPNC) fishing village revealed through microwear analysis of bifacial flint tools from the submerged Atlit-Yam site, Israel. J. Archaeol. Sci. 48, 120-128.

A.A. Evans
Archaeological Sciences, School of Life Sciences, University of Bradford, Bradford BD7 1DP, UK

H. Lerner

Universite Laval, Quebec, Quebec, Canada

D.A. Macdonald

CEPAM, CNRS, Université Nice Sophia Antipolis, 24 avenue des Diables Bleus, Nice 06357, France

W.J. Stemp

Department of Sociology and Anthropology, Keene State College, 229 Main St., Keene, NH 03435-3400, United States

P.C. Anderson

CEPAM, CNRS, Université Nice Sophia Antipolis, 24 avenue des Diables Bleus, Nice 06357, France

${ }^{*}$ Corresponding author. E-mail address: a.a.evans@bradford.ac.uk (A.A. Evans).

Available online 14 March 2014 